\title{
THE IMPACT OF BALINT WORK ON ALEXITHYMIA, PERCEIVED STRESS, PERCEIVED SOCIAL SUPPORT AND BURNOUT AMONG PHYSICIANS WORKING IN PALLIATIVE CARE: A LONGITUDINAL STUDY
}

\section{OVIDIU POPA-VELEA, CARMEN-IOANA TRUȚESCU, and LILIANA VERONICA DIACONESCU}

\author{
University of Medicine and Pharmacy "Carol Davila," Bucharest, Romania \\ Faculty of Medicine, Department of Medical Psychology
}

\begin{abstract}
Objectives: Physicians working with palliative patients have a substantial risk of emotional exhaustion because of their daily confrontation with suffering and death. Common concerns include alexithymia, high stress, low perceived social support and a greater burnout risk. This longitudinal study aimed to evaluate the effectiveness of Balint training in preventing the development of these symptoms in these medical professionals. Material and Methods: The design of the study was longitudinal. A group of 69 physicians working with palliative patients from 5 county hospitals in Romania (33 men, 36 women) participated in the study. Out of them, 31 joined and systematically attended a local Balint group whereas the others did not participate in such a group, either during the study or previously. They were given, both at the beginning (2015) and at the end of the study (2017), 4 psychometric instruments assessing alexithymia (Bagby's Toronto Alexithymia Scale), perceived stress (Cohen and Williamson's Perceived Stress Scale), social support (Duke-UNC Functional Social Support Questionnaire) and burnout (Maslach Burnout Inventory). A split-plot ANOVA analysis was used for evaluating the significance of Balint groups participation, with gender and age considered as auxiliary variables. Results: In the study group, Balint training significantly improved the scores of global burnout $(\mathrm{F}(1,64)=25.104, \mathrm{p}<0.0001), 2$ of its components (emotional exhaustion $(\mathrm{F}(1,64)=18.390, \mathrm{p}<0.0001)$ and depersonalization $(\mathrm{F}(1,64)=10.957, \mathrm{p}<0.002)$, alexithymia $(\mathrm{F}(1,64)=3.461, \mathrm{p}<0.0001)$ and perceived social support $(\mathrm{F}(1,64)=57.883, \mathrm{p}<0.0001)$, but not the scores of perceived stress and low personal accomplishment. Gender had an additional contribution in decreasing alexithymia $(\mathrm{F}(1,64)=7.436, \mathrm{p}<0.009)$ and increasing perceived social support $(\mathrm{F}(1,64)=15.426$, $\mathrm{p}<0.0001)$, with higher effects in men. Conclusions: This study points to the potential usefulness of Balint training in addressing alexithymia and burnout, and in improving perceived social support among physicians working with palliative patients. As the Balint method is easily understood and does not require special investments, it could represent a cost-effective instrument of addressing job-related psychological risks. Int J Occup Med Environ Health. 2019;32(1):53-63
\end{abstract}

Key words:

social support, stress, burnout, palliative care, alexithymia, Balint

\section{INTRODUCTION}

Modern medicine is characterized by a progressive shift from the classical "disease-centered paradigm" to more subtle "personalized" or "patient-centered" care (PCC). This process seems to represent a steady tendency in the long run, as PCC caters better to the preferences of patients [1-4], results in better adherence [5] and satisfac- tion regarding therapy [6], and is associated, especially in chronic diseases, with a better self-reported quality of life $[7,8]$.

However, if performed intensively (especially in the absence of a team, or without appropriate psychological assistance), PCC can be a supplementary risk factor for burnout in medical professionals [9]. Approximately 40-60\%

Received: November 9, 2017. Accepted: May 14, 2018.

Corresponding author: Ovidiu Popa-Velea, University of Medicine and Pharmacy "Carol Davila," Faculty of Medicine, Department of Medical Psychology, Bd Eroilor Sanitari 8, 050474 Bucharest, Romania (e-mail: ovidiu.popa-velea@umfcd.ro). 
of all physicians may be affected by burnout throughout their career [10,11], and this risk is increased by:

- external circumstances, for example organizations characterized by high perceived responsibilities, time pressure and a low level of control, or without wellestablished procedures and methods to overcome the consequences of intensive work involvement [12-14];

- internal variables, such as:

- alexithymia - defined as the "inability to find appropriate words to describe one's feelings" [15,16]. Alexithymia is encouraged by medical education [17] as a part of the "heroic caring stereotype." Once internalized, alexithymia has long-term consequences, such as psychological distress [18], depression, emotional exhaustion and depersonalization $[19,20]$, as well as a higher risk of psychosomatic symptoms [15], with low chances of recovery. It is also related to reduced perceived network support, limited social skills and a reduced capacity to use social interactions for affect regulation [21];

- high levels of perceived stress. Enduring stress is considered a "normal" component of the medical profession, especially in specialties where the patient's vital prognosis comes at play [22];

- lack of social support [23]. This circumstance often arises in medical specialties where therapeutic teams are absent or unstable over time.

The question of burnout vulnerability and how it can be overcome is particularly important for physicians working with palliative patients [24,25]. Not only are these professionals pressed to provide PCC daily, but they also have to overcome the inherent emotional difficulties stemming from the specificity of these cases (e.g., impossibility to cure, repeated exposure to death, fear related to the formation of bonds and then loss of their object, patient's emotional dependence, unpredictable changes during the course of the illness) [26,27]. Once present, burnout symptoms can directly impact on the well-being of patients who may perceive their therapy as less safe and acceptable [28]. Moreover, these changes are aggravated by physicians' unawareness and/or lack of action regarding their own burnout risk, possibly causing a permanent alteration in the nature of the therapeutic relationship [29]. In the case of Romanian physicians, attentiveness to these risks has increased only recently (as palliative care is quite a new specialty); however, the currently high rate of development in this field, with 115 PC services organized nationally in 2018 [30], ensures a steady preoccupation with this topic in the upcoming years.

Taking into consideration the current rise in the number of palliative cases, investigating how we can better support these physicians in delivering PCC, while preventing or overcoming the risk of burnout, represents a meaningful purpose, with the potential to ensure the well-being of all participants in the therapeutic process. In this respect, participating in Balint groups has been reported as an effective way of preventing and addressing burnout in physicians [31-33]. Moreover, this method is typically easy to implement, even in the absence of solid organizational support, making it advantageous in countries where health care resources are limited. This includes Romania, where the number of active Balint groups has increased steadily since the 1990s [34]. Still, scientific studies on Balint group effectiveness for physicians remain rare. They are not focused on a single specialty and use various evaluations of outcomes, thereby making their results difficult to validate or replicate. Even less is known about the particular use of Balint training for addressing burnout in physicians working with palliative patients [35].

This study aimed to assess the direct impact of participation in Balint groups on the burnout risk among Romanian physicians attending palliative patients, and on the psychological factors consistently related to burnout (alexithymia, perceived stress and perceived social sup- 
port). Complementarily, the authors measured the collateral influence which demographic factors (age and gender) may have on the above mentioned variables.

\section{MATERIAL AND METHODS}

The design of the study was longitudinal. At the beginning of the study (June 2014), 92 physicians were randomly pre-selected from those working with palliative patients in 5 county hospitals in Romania. None of these pre-selected physicians had been informed previously about the Balint method or its use. In a distinct series of informative sessions, they were presented with materials about the principles which lie at the basis of the organization of Balint groups, the typical routine of a Balint group meeting and the potential benefits of participating in this kind of activity for medical professionals. From those attending the presentations, 45 expressed an initial interest in the Balint method, and 31 actually participated in 20 or more Balint meetings in January 2015July 2017. In total, they attended 6 Balint groups, run by leaders with a medical professional background and comprising 8-15 stable active members (mostly, but not exclusively, physicians). Due to their systematic interest and involvement, these physicians were considered the study group ("Balintians" - B). In the same period, 38 physicians from the initial sample did not attend Balint groups and were considered the control group ("nonBalintians" - NB). The study group and the control group did not differ significantly in terms of age, gender and years of medical experience (Table 1).

All the participants were administered the following psychological instruments twice, at the beginning of the study $(\mathrm{T} 0=$ January 2015) and at the end (T1 = July 2017).

\section{Bagby's Toronto Alexithymia Scale}

The Bagby's Toronto Alexithymia Scale (TAS-20) [36] is a self-reported questionnaire with 20 items and 3 subscales: "difficulty identifying feelings" (F1), "difficulty describing feelings to others" (F2), and "externally-oriented thinking" (F3), all characteristic for alexithymia. The instrument comprises 3 cut-off points, i.e., $\leq 51-$ no alexithymia, $\geq 61$ - alexithymia, and 52-60 - possible alexithymia. The scale has been reported to have good internal consistency (Cronbach's $\alpha=0.81$ ) and test-retest reliability $(0.77, p<0.01)$, as well as the adequate levels of convergent and concurrent validity $[37,38]$.

Table 1. Participants in the study evaluating the effectiveness of Balint training conducted in Romania in 2015-2017*

\begin{tabular}{|c|c|c|c|c|c|}
\hline \multirow{2}{*}{ Variable } & \multicolumn{2}{|c|}{$\begin{array}{c}\text { Participants } \\
(\mathrm{N}=69)\end{array}$} & \multirow{2}{*}{$t(d f)$} & \multirow{2}{*}{$\chi^{2}(\mathrm{df})$} & \multirow{2}{*}{$\mathrm{p}$} \\
\hline & $\begin{array}{l}\text { study group } \\
\quad(\mathrm{N}=31)\end{array}$ & $\begin{array}{c}\text { control group } \\
(\mathrm{N}=38)\end{array}$ & & & \\
\hline Age [years] & & & $1.198(67)$ & & 0.235 \\
\hline $\mathrm{M} \pm \mathrm{SD}$ & $50.12 \pm 5.74$ & $48.26 \pm 6.94$ & & & \\
\hline $\min .-\max$ & $39-62$ & $34-58$ & & & \\
\hline Gender [n] & & & & $0.007(1)$ & 0.933 \\
\hline male & 15 & 18 & & & \\
\hline female & 16 & 20 & & & \\
\hline Medical experience [years] & & & $0.633(67)$ & & 0.529 \\
\hline $\mathrm{M} \pm \mathrm{SD}$ & $23.35 \pm 4.99$ & $22.42 \pm 6.86$ & & & \\
\hline
\end{tabular}

* There were no significant differences between the study and control groups in terms of age, years of medical experience and gender. 


\section{Cohen and Williamson's Perceived Stress Scale}

The Cohen and Williamson's Perceived Stress Scale (PSS) [39] is a 14-item self-report instrument, designed to measure the degree to which situations in one's life are viewed as stressful. The answers are distributed on a 5-point Likert scale, with total scores of 0-56 (higher scores represent high stress levels). The questionnaire has been described as displaying good convergent validity, high internal consistency and reliability (Cronbach's $\alpha>0.80)[40,41]$.

\section{Duke-UNC Functional}

\section{Social Support Questionnaire}

The Duke-UNC Functional Social Support Questionnaire (FSSQ) [42] is an 8-item instrument that measures the strength of the person's social support network. The scoring is realized on a 1-5 proportional scale (the higher the average score, the greater the perceived social support). The test has high construct validity, and high internal consistency and reliability (with Cronbach's $\alpha=$ 0.89-0.92) [43,44].

\section{Maslach Burnout Inventory}

The Maslach Burnout Inventory (MBI) [45] is the most well-known instrument for the assessment of burnout. It comprises 22 items and 3 subscales: emotional exhaustion (EE), depersonalization (DP) and low personal accomplishment (LPA) (with 9, 5 and 8 items, respectively). The answers are provided on a 7-point, fully anchored scale (from $0=$ "never" up to $6=$ "every day"). Greater burnout is indicated by higher scores on each of the subscales. The test has a good reported test-retest reliability of up to 0.82 , and high validity [46]. In this study, the authors considered the criteria of clinical burnout to be met if the participants had a score above 30 on the EE scale and if at least 1 of the scores of the other 2 dimensions was above the recommended cut-off points $(\mathrm{DP}=11$; $\mathrm{LPA}=35$ ).

\section{Ethics}

The study procedures were considered by the Ethical Boards of all hospitals to be appropriate and in accordance with the ethical standards for human experimentation.

\section{Statistics}

This longitudinal study measured the evolution of the scores for burnout, alexithymia, perceived stress and perceived social support, as dependent variables, in relation to the systematic participation in Balint groups, as the independent variable. Responses were processed using the SPSS Statistics 17.0.1 software package (SPSS, Inc., Chicago, IL, USA). The analysis included firstly a descriptive level, in which the scores of the variables were collected and their evolution throughout the study period was observed. Next, the authors conducted a split-plot analysis of variance (ANOVA) to assess the statistical significance of changes in the participants' perceived stress, perceived social support and burnout (i.e., global burnout and its components), in relation to Balint training. The independent variables included 1 within-groups variable (time, with 2 levels), and 2 betweengroups variables (Balint training and gender, with 2 levels each). Age was introduced in the analysis as a covariate. This statistical procedure made it possible to distinguish between the independent effects of Balint training and gender on the scores of perceived stress, perceived social support, alexithymia and burnout. Also, it was appropriate for testing the effect size, in the form of the Eta ${ }^{2}$ coefficient.

\section{RESULTS}

\section{Descriptive analysis}

In the study group, the mean burnout (global, EE, DP) and perceived stress scores decreased from $\mathrm{T} 0$ to $\mathrm{T} 1$ whereas an opposite outcome was seen in the control group. The mean perceived social support score increased in the study group from $\mathrm{T} 0$ to $\mathrm{T} 1$ whereas in the control group it had a very slight decrease. The means of LPA and alexithymia decreased in both groups that were studied from $\mathrm{T} 0$ to $\mathrm{T} 1$ (Table 2). 
At T0, 20 participants (28.98\%) (9 males and 11 females) met the criteria for clinical burnout. Although this percentage rate remained nearly unchanged at T1 (27.53\%) (9 males and 10 females), the individuals affected by clinical burnout were typically not the same as those at T0. In this respect, the authors noticed a solid positive impact of Balint training, indicated by the ratio $\mathrm{B}: \mathrm{NB}=0.46$ (males 0.28 , females 0.66 ).

\section{Statistical analysis}

The 2 groups did not differ at $\mathrm{T} 0$ with respect to the main variables evaluated in the study, this being proven by t-test scores, which showed no significant differences $(p=0.31-$ 0.98). Instead, at T1, alexithymia, perceived social support and burnout (global score, EE and DP) differed significantly between the participants in the study and control groups ( $\mathrm{p}=0.001-0.005)$ (Table 2$)$.

\section{The effects of Balint training}

The results of the ANOVA analysis showed a significant effect of Balint training on global burnout (Wilks' $\lambda=$ 0.687, $\left.\mathrm{F}(1,64)=25.104, \mathrm{p}<0.0001, \mathrm{Eta}^{2}=0.313\right)$, $\mathrm{EE}($ Wilks' $\lambda=0.749, \mathrm{~F}(1,64)=18.390, \mathrm{p}<0.0001$, $\left.\mathrm{Eta}^{2}=0.251\right)$ and DP $($ Wilks' $\lambda=0.834, \mathrm{~F}(1,64)=10.957$, $\mathrm{p}<0.002, \mathrm{Eta}^{2}=0.166$ ). The same effect was not observed for the LPA component of burnout (Wilks' $\lambda=0.945$, $\left.\mathrm{F}(1,64)=3.189, \mathrm{p}<0.008, \operatorname{Eta}^{2}=0.055\right)($ Table 3$)$.

Balint training had a favorable impact on the scores of alexithymia (Wilks' $\lambda=0.941, \mathrm{~F}(1,64)=3.461$, $\left.\mathrm{p}<0.0001, \mathrm{Eta}^{2}=0.658\right)$ and perceived social support (Wilks' $\lambda=0.487, \mathrm{~F}(1,64)=57.883, \mathrm{p}<0.0001, \mathrm{Eta}^{2}=$ $0.513)$. In contrast, the changes in participants' perceived stress were not predicted by Balint training (Table 4).

\section{Gender differences}

The ANOVA analysis showed, in the case of certain variables, a significant impact of gender alongside Balint training (Table 4). This included alexithymia (Wilks' $\lambda=0.881$,

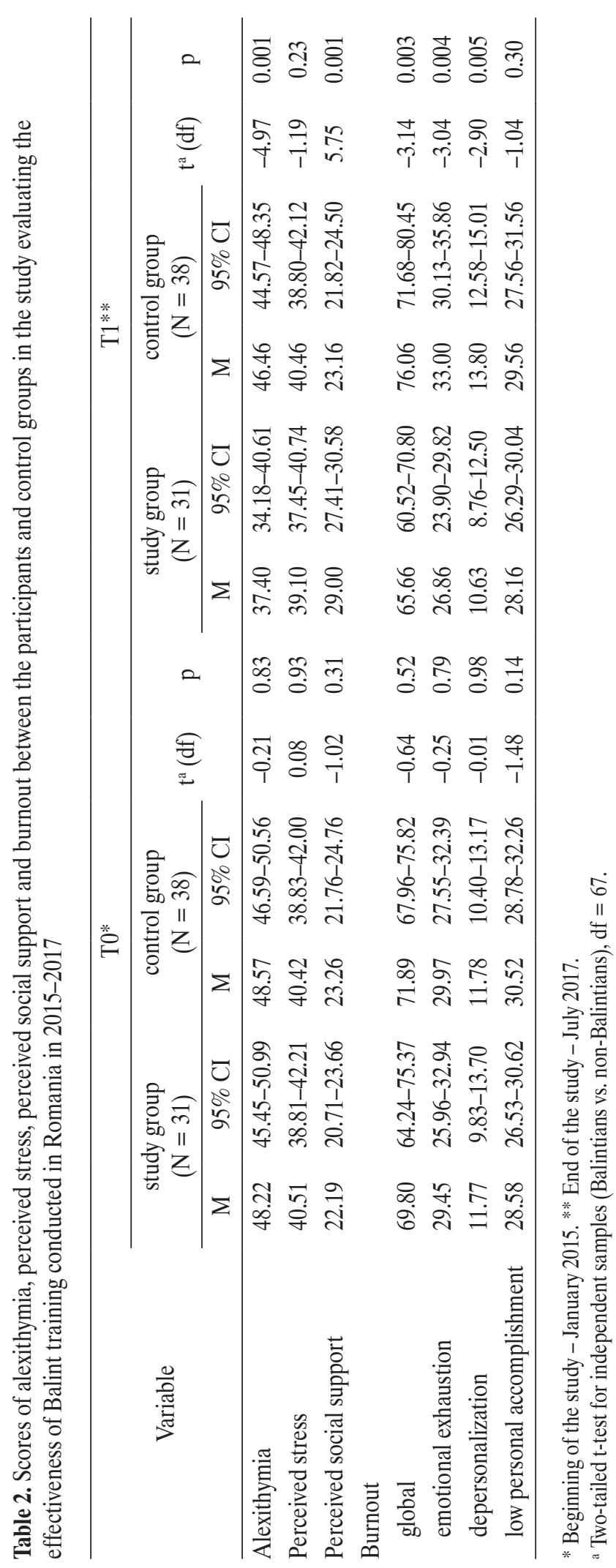


Table 3. Repeated measure split-plot analysis of variance (ANOVA) for burnout and its components ${ }^{\mathrm{a}}$

\begin{tabular}{lcccc}
\hline \multicolumn{1}{c}{ Burnout/Source of variance } & $\mathrm{M}^{2}$ & $\mathrm{~F}$ & $\mathrm{p}$ & Eta $^{2}$ \\
\hline Global & & & & \\
time & 8.918 & 0.476 & 0.493 & 0.009 \\
time $\times$ age & 7.418 & 0.396 & 0.532 & 0.007 \\
time $\times$ Balint training & 469.938 & 25.104 & 0.0001 & 0.313 \\
time $\times$ gender & 1.164 & 0.062 & 0.804 & 0.001 \\
time $\times$ Balint training $\times$ gender & 8.663 & 0.463 & 0.499 & 0.008 \\
Emotional exhaustion & & & & \\
time & 8.135 & 0.597 & 0.443 & 0.011 \\
time $\times$ age & 8.369 & 0.614 & 0.437 & 0.011 \\
time $\times$ Balint training & 250.673 & 18.390 & 0.0001 & 0.251 \\
time $\times$ gender & 10.986 & 0.806 & 0.373 & 0.014 \\
time $\times$ Balint training $\times$ gender & 6.034 & 0.443 & 0.509 & 0.008 \\
Depersonalization & & & & \\
time & 0.596 & 0.065 & 0.800 & 0.001 \\
time $\times$ age & 0.073 & 0.008 & 0.929 & 0.000 \\
time $\times$ Balint training & 100.606 & 10.957 & 0.002 & 0.166 \\
time $\times$ gender & 4.064 & 0.443 & 0.509 & 0.008 \\
time $\times$ Balint training $\times$ gender & 0.337 & 0.037 & 0.849 & 0.001 \\
Low personal accomplishment & & & & 0.008 \\
time & 10.292 & 1.635 & 0.206 & 0.029 \\
time $\times$ age & 19.841 & 3.152 & 0.081 & 0.054 \\
time $\times$ Balint training & 12.049 & 1.914 & 0.172 & 0.034 \\
time $\times$ gender & & & \\
time $\times$ Balint training $\times$ gender & 2.692 & 0.428 & 0.516 & 0.397 \\
\hline
\end{tabular}

${ }^{a} \mathrm{df} 1$.

Table 4. Repeated measure split-plot analysis of variance (ANOVA) for alexithymia, perceived stress and perceived social support ${ }^{\mathrm{a}}$

\begin{tabular}{lcccc}
\hline \multicolumn{1}{r}{ Variable/Source of variance } & $\mathrm{M}^{2}$ & $\mathrm{~F}$ & $\mathrm{p}$ & Eta $^{2}$ \\
\hline Alexithymia & & & & \\
$\quad$ time & 18.428 & 3.461 & 0.068 & 0.059 \\
time $\times$ age & 0.047 & 0.009 & 0.925 & 0.000 \\
time $\times$ Balint training & 562.595 & 105.654 & 0.0001 & 0.658 \\
time $\times$ gender & 39.595 & 7.436 & 0.009 & 0.119 \\
time $\times$ Balint training $\times$ gender & 182.836 & 34.336 & 0.0001 & 0.384 \\
\hline
\end{tabular}


Table 4. Repeated measure split-plot analysis of variance (ANOVA) for alexithymia, perceived stress and perceived social support ${ }^{\mathrm{a}}$ - cont.

\begin{tabular}{lcccc}
\hline \multicolumn{1}{r}{ Variable/Source of variance } & $\mathrm{M}^{2}$ & $\mathrm{~F}$ & $\mathrm{p}$ & Eta $^{2}$ \\
\hline Perceived stress & & & & \\
$\quad$ time & 2.692 & 0.428 & 0.516 & 0.008 \\
time $\times$ age & 4.594 & 0.730 & 0.397 & 0.013 \\
time $\times$ Balint training & 10.292 & 1.635 & 0.206 & 0.029 \\
time $\times$ gender & 19.841 & 3.152 & 0.081 & 0.054 \\
time $\times$ Balint training $\times$ gender & 12.049 & 1.914 & 0.172 & 0.034 \\
Perceived social support & & & & \\
time & 0.394 & 0.068 & 0.795 & 0.001 \\
time $\times$ age & 3.041 & 0.527 & 0.471 & 0.009 \\
time $\times$ Balint training & 333.879 & 57.883 & 0.0001 & 0.513 \\
time $\times$ gender & 87.943 & 15.426 & 0.0001 & 0.217 \\
time $\times$ Balint training $\times$ gender & 26.269 & 4.554 & 0.037 & 0.076 \\
\hline
\end{tabular}

${ }^{a}$ df 1.

$\left.\mathrm{F}(1,64)=7.436, \mathrm{p}<0.009, \mathrm{Eta}^{2}=0.119\right)$, with a higher decrease in men (mean difference T1-T0 $=-7.785$ [95\% CI: $-10.877-(-4.693)])$ compared to women (mean difference T1-T0 $=-5.468$ [95\% CI: $-6.594-(-4.343)])$. Similarly, gender played a significant additional role to Balint training when it comes to the increase in perceived social support (Wilks' $\left.\lambda=0.783, \mathrm{~F}(1,64)=15.426, \mathrm{p}<0.0001, \mathrm{Eta}^{2}=0.217\right)$. The increase was higher in men (mean difference T1-T0 $=5.214$ [95\% CI: 3.055-7.372]) compared to women (mean difference $\mathrm{T} 1-\mathrm{T} 0=1.718$ [95\% CI: 0.227-3.210]).

The Balint training $\times$ gender interaction had a marginal statistical significance $(p<0.052)$ regarding the feeling of low personal accomplishment. Oppositely, there were no significant gender-related differences regarding the other 2 components of burnout (EE, DP) and the burnout global score (Table 3). The impact of gender on the variations of perceived stress was not significant (Table 4).

\section{DISCUSSION}

This study aimed to evaluate the impact of Balint training on alexithymia, perceived stress, perceived social support and burnout among physicians working with palliative patients. Although burnout as a clinical phenomenon remained unchanged in terms of frequency throughout the study (around 30\%), participating in Balint groups seems to have had a protective role, in the sense that the prevalence of clinical burnout among Balint trainees was much lower compared to the control group. Statistically, the decrease in burnout scores attributable to Balint training was significant, not only in terms of the global score, but also concerning emotional exhaustion and depersonalization. A similar positive impact was observed when analyzing the distinct impact of Balint training on alexithymia and perceived social support. Alexithymia scores decreased significantly, corresponding to a process of unlocking emotional expressions which, in turn, may prevent serious illness [47]. Oppositely, perceived social support significantly increased in Balint trainees, potentially leading to a higher chance of health benefits derived from its commonly acknowledged buffer role against stress [48]. For both alexithymia and perceived social support, the positive effects of Balint training were influenced by gender, with a higher impact in men than in women. This finding could be due to the alternative means women have for preventing or addressing 
alexithymia, and for addressing those circumstances when social support becomes inadequate. Among such strategies, the literature mentions their higher propensity for building local networks in order to obtain help and their better efficiency in using them [49].

In terms of perceived stress, this dimension was not influenced by Balint participation. Balint training, which is typically focused on medically-related circumstances, may not have been effective in addressing the multiple sources of stress to which Romanian physicians are exposed outside of the medical profession.

Similarly, low personal accomplishment was not influenced by Balint training. This could be explained by other societal variables (e.g., low income, lack of facilities, poor social recognition), which are commonly reported by Romanian physicians as sources of personal unhappiness and vocational dissatisfaction [50].

\section{Limitations}

This study had several limitations. The sample size was rather small, so the generalization of findings should be made with caution. The attendance threshold for being considered a "Balintian" was established by the study authors. Among the psychological variables potentially influenced by Balint participation, only alexithymia, perceived stress, perceived social support and burnout were taken into account, although the spectrum of Balint influence could have been larger. Similarly, when testing the impact of gender on variables such as perceived social support, one should also consider collateral variables, such as marital status, which could significantly influence the degree of perceived social support, at least in the case of women [51].

Despite its limitations, the analysis has the merit of a longitudinal design, multi-centricity and a gender-specific investigation of Balint influence. Its results could be used in an organizational climate which is not yet established and which could potentially offer a good opportunity for changes in the way physicians' mental health is improved, and the subsequent evaluation of the impact of these changes. Ideally, this could supplement physicians' personal strategies for coping with professional stress, and eventually contribute to better psychological comfort and satisfaction with care, both among physicians and their patients.

\section{CONCLUSIONS}

The global effects of Balint training for Romanian physicians working with palliative patients are favorable, at least regarding alexithymia, perceived social support and burnout. Some of these effects are gender-specific, which would require further research in order to better understand the underlying mechanisms of this asymmetry. As a whole, the results of this study offer reasons for optimism, paving the way for preventive action in a field traditionally perceived as demanding and entailing a high risk of developing mental exhaustion. Since Balint training can be typically implemented without extravagant costs, these findings are encouraging further development of patientcentered care.

\section{ACKNOWLEDGMENTS}

The authors would like to warmly thank Dr. Albert Veress for the precious theoretical guidance offered throughout the study.

\section{REFERENCES}

1. Gibson PG, Powell H, Coughlan J, Wilson AJ, Abramson M, Haywood P, et al. Self-management education and regular practitioner review for adults with asthma. Cochrane Database Syst Rev. 2003;1:CD001117, https://doi.org/10.1002/14651858. CD001117.

2. Guadagnoli E, Ward P. Patient participation in decision-making. Soc Sci Med. 1998;47(3):329-39, https://doi.org/10.1016/ S0277-9536(98)00059-8.

3. Beaver K, Bogg J, Luker KA. Decision-making role preferences and information needs: A comparison of colorectal and breast cancer. Health Expect. 1999;2(4):266-76, https://doi. org/10.1046/j.1369-6513.1999.00066.x. 
4. Kenny P, Quine S, Shiell A, Cameron S. Participation in treatment decision-making by women with early stage breast cancer. Health Expect. 1999;2(3):159-68, https://doi. org/10.1046/j.1369-6513.1999.00050.x.

5. Robinson JH, Callister LC, Berry JA, Dearing KA. Patientcentered care and adherence: Definitions and applications to improve outcomes. J Am Acad Nurse Pract. 2008;20(12):6007, https://doi.org/10.1111/j.1745-7599.2008.00360.x.

6. Berman AT, Rosenthal SA, Moghanaki D, Woodhouse KD, Movsas B, Vapiwala N. Focusing on the "person" in personalized medicine: The future of patient-centered care in radiation oncology. J Am Coll Radiol 2016;13(12 PtB):1571-8, https://doi.org/10.1016/j.jacr.2016.09.012.

7. Suhonen R, Välimäki M, Leino-Kilpi H. Individualized care, quality of life and satisfaction with nursing care. J Adv Nurs 2005;50(3):283-92, https://doi.org/10.1111/j.1365-2648. 2005.03391.x.

8. Williams JS, Walker RJ, Smalls BL, Hill R, Egede LE. Patient-centered care, glycemic control, diabetes self-care, and quality of life in adults with type 2 diabetes. Diabetes Technol Ther. 2016;18(10):644-9, https://doi.org/10.1089/dia. 2016.0079.

9. Lewis SE, Nocon RS, Tang H, Park SY, Vable AM, Casalino LP. Patient-centered medical home characteristics and staff morale in safety net clinics. Arch Intern Med. 2012;172(1):23-31, https://doi.org/10.1001/archintern med.2011.580.

10. Ramirez AJ, Graham J, Richards MA, Cull A, Gregory WM, Leaning MS, et al. Burnout and psychiatric disorder among cancer clinicians. Br J Cancer. 1995;71(6):1263-9, https:// doi.org/10.1038/bjc.1995.244.

11. Shanafelt TD, Boone S, Tan L, Dyrbye LN, Sotile W, Satele D, et al. Burnout and satisfaction with work-life balance among US physicians relative to the general US population. Arch Intern Med. 2012;172(18):1377-85, https://doi. org/10.1001/archinternmed.2012.3199

12. Arsenault A, Dolan SL, van Ameringen MR. Stress and mental strain in hospital work: Exploring the relationship beyond personality. J Organ Behav. 1991;12(6):483-93, https://doi.org/10.1002/job.4030120603.

13. Polman R, Borkoles E, Nicholls AR. Type D personality, stress, and symptoms of burnout: The influence of avoidance coping and social support. Br J Health Psychol. 2010;15(Pt3): 681-96, https://doi.org/10.1348/135910709X479069.

14. Isaksson Ro KE, Tyssen R, Hoffart A, Sexton H, Aasland OG, Gude T. A three-year cohort study of the relationships between coping, job stress and burnout after a counselling intervention for help-seeking physicians. BMC Public Health. 2010;10:213, https://doi.org/10.1186/14712458-10-213.

15. Sifneos PE. The prevalence of alexithymic characteristics in psychosomatic patients. Psychother Psychosom 1973;22 (2-6):255-62, https://doi.org/10.1159/000286529.

16. Taylor GJ, Bagby RM, Parker JDA. Disorders of affect regulation: Alexithymia in medical and psychiatric illness. Cambridge: Cambridge University Press; 1997, https://doi. org/10.1017/CBO9780511526831.

17. Shapiro J. Does medical education promote professional alexithymia? A call for attending to the emotions of patients and self in medical training. Acad Med. 2011;86(3):326-32, https://doi.org/10.1097/ACM.0b013e3182088833.

18. Kokkonen P, Karvonen JT, Veijola J, Lasky K, Jokelainen J, Jarvelin MR, et al. Prevalence and sociodemographic correlates of alexithymia in a population sample of young adults. Compr Psychiatry. 2001;42(6):471-6, https://doi.org/10.1053/ comp.2001.27892.

19. Bratis D, Tselebis A, Sikaras C, Moulou A, Giotakis K, Zoumakis E, et al. Alexithymia and its association with burnout, depression and family support among Greek nursing staff. Hum Resour Health. 2009;11(7):72, https://doi. org/10.1186/1478-4491-7-72.

20. Mattila AK, Ahola K, Honkonen T, Salminen JK, Huhtala H, Joukamaa M. Alexithymia and occupational burnout are strongly associated in working population. J Psychosom Res. 2007;62(6):657-65, https://doi.org/10.1016/j.jpsychores.2007.01.002. 
21. Lumley MA, Ovies T, Stettner L, Wehmer F, Lakey B. Alexithymia, social support and health problems. J Psychosom Res. 1996;41(6):519-30, https://doi.org/10.1016/S00223999(96)00227-9.

22. Coomber S, Todd C, Park G, Baxter P, Firth-Cozens J, Shore S. Stress in UK intensive care unit doctors. Br J Anaesth. 2002;89(6):873-81, https://doi.org/10.1093/bja/aef273.

23. Gustafsson G, Eriksson S, Strandberg G, Norberg A. Burnout and perceptions of conscience among health care personnel: A pilot study. Nurs Ethics. 2010;17(1):23-38, https:// doi.org/10.1177/0969733009351950.

24. Mathe T, Moşoiu D. [Staff burnout syndrome in onco-pediatrics departments, ICU and pediatric palliative care settings]. Jurnal Medical Braşovean (JMR) 2013;2:55-8. Romanian.

25. Dobre C, Duceac L, Grierosu C, Mihai D, Zaharia A, Stafie $\mathrm{L}$ et al. Efficient measures for burnout prevention in palliative care. Int J Med Dent. 2017;7(2):81-4.

26. Riordan RJ, Saltzer SK. Burnout prevention among healthcare providers working with the terminally ill: A literature review. Omega. 1992;25(1):17-24, https://doi.org/10.2190/ EQ6R-GX93-PW34-JTKE.

27. Ross MW, Seeger V. Determinants of reported burnout in health professionals associated with the care of patients with AIDS. AIDS. 1988;2(5):395-7, https://doi. org/10.1097/00002030-198810000-00012.

28. Dewa CS, Loong D, Bonato S, Trojanowski L. The relationship between physician burnout and quality of healthcare in terms of safety and acceptability: A systematic review. BMJ Open. 2017;7(6):e015141, https://doi.org/10.1136/bmjopen-2016-015141.

29. Meier DE, Back AL, Morrison RS. The inner life of physicians and care of the seriously ill. JAMA. 2001;286(23):300714, https://doi.org/10.1001/jama.286.23.3007.

30. Moşoiu D, Mitrea N, Dumitrescu M. Palliative care in Romania. J Pain Symptom Manage. 2018;55 (suppl 2):S67-76, https://doi.org/10.1016/j.jpainsymman.2017.03.036.

31. Kjeldmand D, Holmström I. Balint groups as a means to increase job satisfaction and prevent burnout among general practitioners. Ann Fam Med. 2008;6(2):138-45, https://doi. org/10.1370/afm.813.

32. Ghetti C, Chang J, Gosman G. Burnout, psychological skills, and empathy: Balint training in obstetrics and gynecology residents. J Grad Med Educ. 2009;1(2):231-5, https://doi. org/10.4300/JGME-D-09-00049.1.

33. Benson J, Magraith K. Compassion fatigue and burnout: The role of Balint groups. Aust Fam Physician. 2005;34(6):497-8.

34. Hegyi C. "Balint" - Întrebări şi răspunsuri. In: Veress A, Hegyi, C, editors. Balint - Întrebări şi răspunsuri - Îndreptar de teorie şi practică despre activitatea Balint. Miercurea Ciuc: Alutus; 2006. p.11-23. Romanian.

35. Knowlton K, Katz, RS. Balint groups to address countertransference and burnout in palliative and end-of-life care. In: Katz RS, Johnson TA, editors. When professionals weep: Emotional and countertransference responses in palliative and end-of-life care. 2nd ed. New York: Routledge; 2016. p.189-92.

36. Bagby RM, Taylor GJ, Parker JD. The twenty-item Toronto Alexithymia Scale - II. Convergent, discriminant and concurrent validity. J Psychosom Res. 1994;38(1):33-40, https:// doi.org/10.1016/0022-3999(94)90006-X.

37. Parker JD, Taylor GJ, Bagby RM. The 20-Item Toronto Alexithymia Scale. III. Reliability and factorial validity in a community population. J Psychosom Res. 2003;55(3):26975, https://doi.org/10.1016/S0022-3999(02)00578-0.

38. Taylor GJ, Bagby RM, Luminet O. Assessment of alexithymia: Self-report and observer-rated scales. In: Bar-On R, Parker JDA, editors. The handbook of emotional intelligence. San Francisco: Jossey-Bass; 2000. p. 301-19.

39. Cohen S, Kamarck T, Mermelstein R. A global measure of perceived stress. J Health Soc Behav. 1983;24(4):385-96, https://doi.org/10.2307/2136404.

40. Mimura C, Griffiths P. A Japanese version of the perceived stress scale: Translation and preliminary test. Int J Nurs Stud. 2004;41(4):379-85, https://doi.org/10.1016/ j.ijnurstu.2003.10.009.

41. Mitchell AM, Crane P, Kim Y. Perceived stress in survivors of suicide: Psychometric properties of the perceived stress 
scale. Res Nurs Health. 2008;31(6):576-85, https://doi.org/ 10.1002/nur.20284.

42. Broadhead WE, Gehlbach SH, DeGruy FV, Kaplan BH. The Duke-UNC Functional Social Support Questionnaire. Measurement of social support in family medicine patients. Med Care. 1988;26(7):709-23, https://doi.org/10.1097/00005650198807000-00006.

43. Liu L, Pang R, Sun W, Wu M, Qu P, Lu C, et al. Functional social support, psychological capital, and depressive and anxiety symptoms among people living with HIV/AIDS employed full-time. BMC Psychiatry. 2013;13:324, https://doi. org/10.1186/1471-244X-13-324.

44. Choi EK, Yoon SJ, Kim JH, Park HJ, Kim JY, Yu ES. Depression and distress in caregivers of children with brain tumors undergoing treatment: Psychosocial factors as moderators. Psychooncology. 2016;25(5):44-50, https://doi. org/10.1002/pon.3962.

45. Maslach C, Jackson SE. Maslach Burnout Inventory. 2nd ed. Palo Alto: Consulting Psychologists Press; 1986. p. 192-215. 46. Rafferty JP, Lemkau JP, Purdy RR, Rudisill JR. Validity of the Maslach Burnout Inventory for family practice physicians. J Clin Psychol. 1986;42(3):488-92, https://doi. org/10.1002/1097-4679(198605)42:3<488::AID-JCLP227 0420315>3.0.CO;2-S.
47. Tolmunen T, Lehto SM, Heliste M, Kurl S, Kauhanen J. Alexithymia is associated with increased cardiovascular mortality in middle-aged Finnish men. Psychosom Med. 2010;72(2): 187-91, https://doi.org/10.1097/PSY.0b013e3181c65d00.

48. Taylor SE. Social support: A review. In Friedman HS, editor. The Oxford handbook of health psychology. Oxford: Oxford University Press; 2011. p. 189-207, https://doi.org/10.1093/ oxfordhb/9780195342819.013.0009.

49. Flaherty J, Richman J. Gender differences in the perception and utilization of social support: Theoretical perspectives and an empirical test. Soc Sci Med. 1989;28(12):1221-8, https://doi.org/10.1016/0277-9536(89)90340-7.

50. Boncea I. Brain drain in Romania: Factors influencing physicians' emigration. J Community Positive Pract (JCPP) [Internet]. 2014;14(1):64-74 [cited 2017 Oct 25]. Available from: http://www.jppc.ro/reviste/JCPP\%20Nr.\%201\%202014/ articole/art06.pdf.

51. Bradbury TN, Fincham FD, Beach SRH. Research on the nature and determinants of marital satisfaction: A decade in review. J Marriage Fam. 2000;62(4):964-80, https://doi. org/10.1111/j.1741-3737.2000.00964.x.

This work is available in Open Access model and licensed under a Creative Commons Attribution-NonCommercial 3.0 Poland License - http://creativecommons.org/ licenses/by-nc/3.0/pl/deed.en. 